\title{
АНАЛИЗ ПРОБЛЕМ НЕСООТВЕТСТВИЯ ИСПОЛЬЗОВАНИЯ ЗЕМЕЛЬ ОБЩЕГО ПОЛЬЗОВАНИЯ САДОВОДЧЕСКОГО ТОВАРИЩЕСТВА «МЕМОРИАЛ-4» НОРМАТИВНЫМ ТРЕБОВАНИЯМ
}

\section{Кристина Игоревна Чалдаева}

Национальный исследовательский Томский политехнический университет, 634034, Россия, г. Томск, ул. Ленина, 30, обучающийся, тел. (999)618-82-08, e-mail: kristusha_ch99@mail.ru

В статье проведен анализ проблем несоответствия использования земель общего пользования современным нормативным требованиям в садоводческом некоммерческом товариществе «Мемориал-4», расположенном в окрестности п. Апрель Томской области. В работе представлен анализ нормативно-правовых документов, регулирующих организацию территорий садоводческих некоммерческих товариществ. Выявлены проблемы несоответствия использования земель общего пользования (в том числе установлены их причины), а также разработаны рекомендации по устранению выявленных проблем с учетом современных реформ нормативно-правовой базы. Выявленные проблемы на территории садоводческого товарищества затрудняют жизнедеятельность граждан, ограничивая возможность подъезда не только легкового транспорта, но и транспорта для технического обслуживания к земельным участкам. Исходными данными для проведения исследования стали результаты геодезической съемки, генеральный план садоводческого товарищества «Мемориал-4» и космоснимки территории товарищества. Для обработки и анализа данных использовано программное обеспечение: ArcGis, AutoCAD. Результаты исследования могут быть использованы при подготовке проектной документации для территорий садоводческих некоммерческих товариществ.

Ключевые слова: земли общего пользования, садоводческое некоммерческое товарищество, проект межевания территории

\section{ANALYSIS OF PROBLEMS OF NON-COMPLIANCE OF THE USE OF PUBLIC LANDS OF THE HORTICULTURAL PARTNERSHIP "MEMORIAL-4" WITH REGULATORY REQUIREMENTS}

\section{Kristina I. Chaldaeva}

National Research Tomsk Polytechnic University, 30, Lenina St., Tomsk, 634034, Russia, Student, phone: (999)618-82-08, e-mail: kristusha_ch99@mail.ru

The article analyzes the problems of inconsistency in the use of common lands with modern regulatory requirements in the horticultural non-profit partnership "Memorial-4", located in the vicinity of the village of April, Tomsk region. The paper presents an analysis of the legal documents governing the organization of territories of horticultural non-profit partnerships. The problems of inconsistency in the use of common lands were identified (including their causes), and recommendations were developed to eliminate the identified problems, taking into account modern reforms of the regulatory framework. The identified problems on the territory of the horticultural partnership impede the life of citizens, limiting the possibility of access not only for cars, but also for maintenance vehicles to land plots. The initial data for the study were the results of geodetic surveys, general plan of the horticultural partnership "Memorial-4" and satellite images of the territory of the partnership. The 
following software was used for data processing and analysis: ArcGis, AutoCAD. The research results can be used in the preparation of design documentation for the territories of horticultural nonprofit partnerships.

Keywords: common land, horticultural non-profit partnership, land surveying project

\section{Введение}

На сегодняшний день одной из главных проблем садоводческих некоммерческих товариществ является несоответствие использования земель общего пользования современным нормативным требованиям. В соответствии с «Земельным кодексом Российской Федерации» от 25.10.2001 №136-Ф3 (ред. от 27.12.2019) к землям общего пользования относятся земли, занятые дорогами, улицами, проездами (в пределах красных линий), пожарными водоемами, а также площадками и участками объектов общего пользования, включая их санитарно-защитные зоны [1].

В настоящее время регулирование застройки территории СНТ осуществляется в соответствии с СП 53.13330.2019 «Планировка и застройка территории ведения гражданами садоводства. Здания и сооружения (СНиП 30-02-97* Планировка и застройка территорий садоводческих (дачных) объединений граждан, здания и сооружения)». Положения настоящего СП 53.13330.2019 направлены на обеспечение пожарной и санитарной безопасности территорий садоводческих (дачных) товариществ и призваны обеспечить формирование комфортной садоводческой деятельности граждан [2]. Как показывает практика, организация территории и застройки в садоводческих некоммерческих товариществах очень часто не соответствует таким нормативным требованиям. Основными причинами этого является тот факт, что нормативные требования появились лишь в конце 90-х годов прошлого столетия, а садовые и дачные товарищества появились в России значительно раньше [3]. В связи с этим актуальной задачей является выявление проблем организации территории и застройки в садоводческих некоммерческих товариществах и разработка предложений по решению выявленных проблем.

Целью настоящей работы является анализ проблем несоответствия использования земель общего пользования садоводческих некоммерческих товариществ нормативным требованиям и разработка рекомендаций по их решению.

Практическая значимость настоящей работы направлена на обеспечение комфортных и безопасных, условий жизнедеятельностИ граждан садоводческих товариществ, а результаты работы могут быть использованы при подготовке проектной документации на территорию товариществ [5].

Объектом исследования является территория садоводческого товарищества «Мемориал-4», расположенного в окрестности п. Апрель Томской области.

Садовое некоммерческое товарищество «Мемориал-4» было образовано в 1995 году и расположено в окрестности микрорайона Апрель Томского района Томской области (рис. 1). Садовое некоммерческое товарищество находится в границах кадастрового квартала с кадастровым номером - 70:14:0341024. 
Территория исследуемого объекта расположена на землях сельскохозяйственного назначения. Согласно карте градостроительного зонирования Богашевского сельского поселения садовое некоммерческое товарищество «Мемориал-4», расположено в зоне CX-3 - зона садовых и дачных участков.

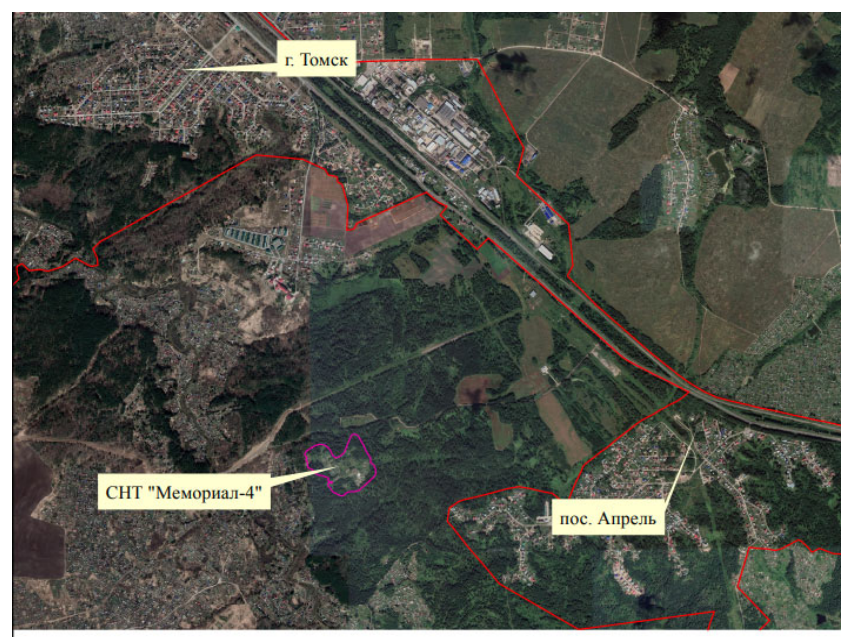

Рис. 1. Схема расположения СНТ «Мемориал-4»

На сегодняшний день на территории СНТ «Мемориал-4» имеется 2 улицы это улица Нижняя, соединяющая СНТ «Василек-79» и СНТ «Мемориал-4» и улица Сосновая, расположенная в пределах исследуемой территории, однако согласно генеральному плану на территории товарищества было запроектировано три улицы.

На территории исследуемого садоводческого товарищества расположено 7 тупиковых проездов, соединяющих соседние земельные участки между собой. Длина таких проездов варьируется от 150 до 300 метров [1].

\section{Методы и материалы}

Для достижения поставленной цели были использованы результаты геодезической съемки, отображающие организацию застройки садоводческого товарищества; данные генерального плана СНТ «Мемориал-4», разработанного в 1995 году, и космоснимки для наглядного отображения ситуации.

В ходе работы был проведен анализ нормативно-правовой базы, регламентирующей застройку территории садоводческих товариществ, а именно СП 53.13330 .2019 «Планировка и застройка территории ведения гражданами садоводства. Здания и сооружения (СНиП 30-02-97* Планировка и застройка территорий садоводческих (дачных) объединений граждан, здания и сооружения)», СП 99.13330.2016 Внутрихозяйственные автомобильные дороги в колхозах, совхозах и других сельскохозяйственных предприятиях и организациях. Актуализированная редакция СНиП 2.05.11-83, в том числе Федеральный закон от 29.07.2017 №217-Ф3 «О ведении гражданами садоводства и огородничества». Для установления выявленных проблем были сопоставлены данные 
генерального плана СНТ «Мемориал-4», разработанного на момент создания товарищества и данные геодезической съемки, полученные в 2019.

В ходе проведенного исследования были выявлены следующие проблемы.

Первой проблемой является несоответствие ширины улиц и проездов настоящему своду правил. На момент создания садоводческого товарищества «Мемориал-4» были актуальны и действовали такие документы, как: СНиП 2.05.11-83 «Внутрихозяйственные автомобильные дороги в колхозах, совхозах и других сельскохозяйственных предприятиях, и организациях» и ВСН 43-85** «Застройка территорий коллективных садов, здания и сооружения. Нормы проектирования» [6]. В соответствии с данными документами минимальная ширина полосы движения в садовых товариществах должна быть 3,5 метра, при условии, что ширина колеи транспортных средств, самоходных и прицепных машин 2,7 метра и менее; максимальная - 5,5 метров, при условии, что ширина колеи от 3,6 метров [1]. На момент создания СНТ «Мемориал-4» минимальная ширина полосы движения составляла 4 метра, при этом возможность проезда транспорта для технического обслуживания не учитывалась. Однако на сегодняшний день, по данным геодезической съемки, проводимой в СНТ «Мемориал-4», оказалось, что минимальная ширина полосы движения транспортных средств составляет на отдельных участках дороги от 3,5 до 3,7 метров. Это создает определенные трудности при подъезде к отдельным земельным участкам на территории СНТ «Мемориал-4» спецтехники, в том числе и пожарных автомобилей, габаритные размеры, которых в настоящее время увеличились [7].

Сужение улиц и проездов на отдельных участках, связано с самовольным захватом земель общего пользования, правообладателями земельных участков.

Сопоставление данных геодезической съемки и данных генерального плана товарищества представлено на рис. 2 .

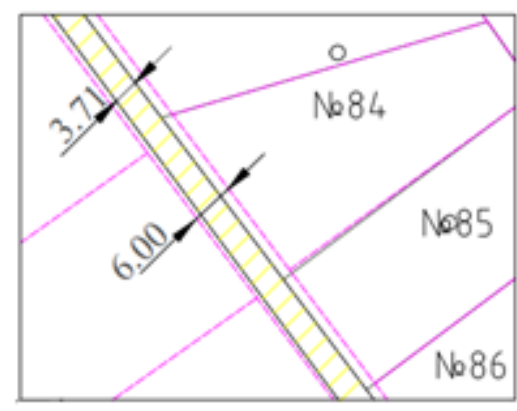

данные генерального планна

данные геодезической сьемюя

Рис. 2. Сопоставление данных геодезической съемки и данных генерального плана товарищества

Вторая проблема заключается в том, что на территории «Мемориал-4» имеются тупиковые проезды, протяженность которых, превышает необходимые требования СП 53.13330.2019 (рис. 3). По данным актуального свода правил протяженность тупикового проезда должна составлять не более 150 метров [1]. Однако 
данные геодезической съемки свидетельствуют о том, что протяженность большего числа проездов, расположенных на территории садоводческого товарищества, варьируется от 180 до 290 метров.

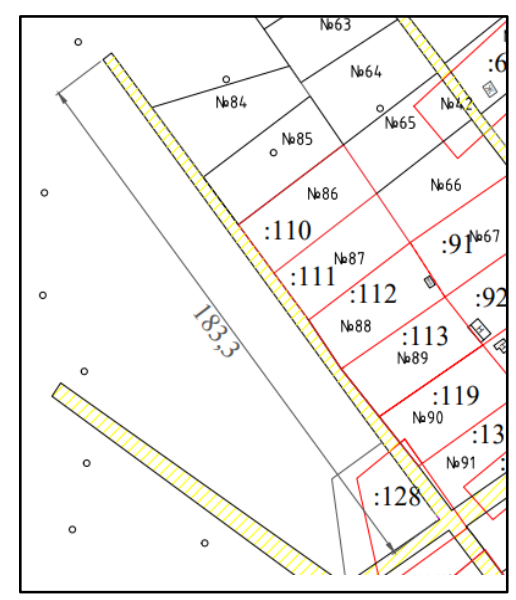

Рис. 3. Протяженность тупикового проезда превышает допустимые нормы

Тупиковые проезды, протяженность которых удовлетворяет нормам СП 53.13330.2019, должны быть обеспечены разворотными площадками для пожарной техники [1]. Результаты исследований свидетельствуют об ее отсутствии (рис. 4). Данная площадка не была предусмотрена при проектировании товарищества, о чем свидетельствуют сопоставление данных геодезической съемки и данных генерального плана.

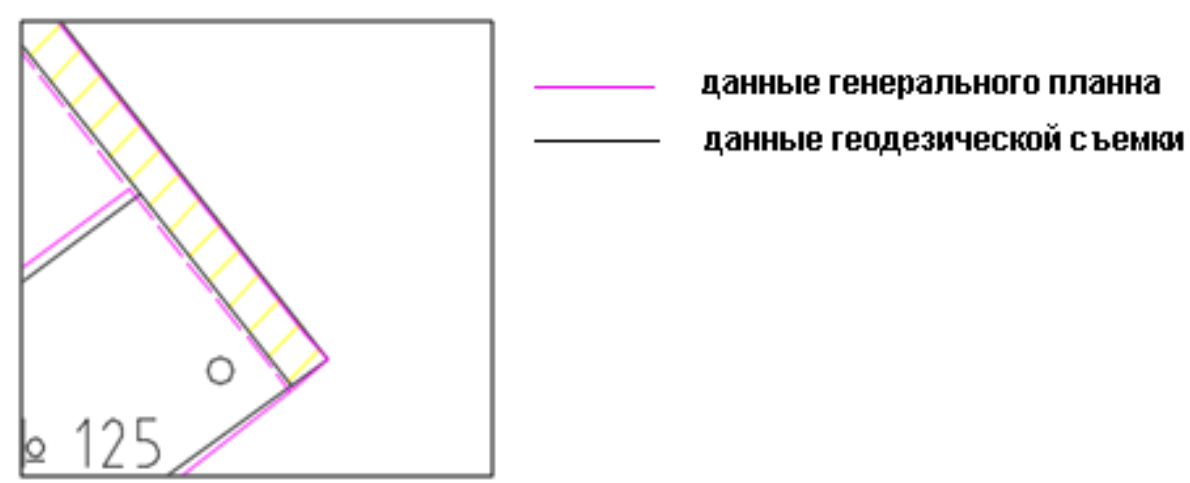

Рис. 4. Отсутствие разворотной площадки

Выявленные проблемы влияют не только на движение спецтехники и пожарного транспорта, но и приводят к тому, что легковой автомобиль не может свободно маневрировать на землях общего пользования территории СНT «Мемориал-4» [8]. 
Третьей проблемой является близкое расположение контейнерной площадки к границам земельных участков. Существующее местоположение данной площадки приводит к нарушению гигиенических норм и правил. В соответствии с СП 53.13330.2011 Планировка и застройка территорий садоводческих (дачных) объединений граждан, здания и сооружения. Актуализированная редакция СНиП 30-02-97* [3] данная площадка должна быть размещена на землях общего пользования, а минимальное расстояние от границ земельных участков до контейнерной площадки должно быть не менее 20 метров [9].

\section{Заключение}

Решение выявленных в ходе исследования проблем, связанных с использованием земель общего пользования на территории садоводческого товарищества «Мемориал-4», имеет первостепенное значение в организации рационального использования земель и регулировании земельных отношений [10].

Результатом решения выявленных проблем стала разработка проекта межевания территории с учетом современных норм и требований и стесненных условий организации территории СНТ «Мемориал-4» [11].

Перед разработкой проекта межевания территории необходимо предложить меры по их устранению, которые заключаются в следующем.

Проблемы, выявленные на территории садоводческого некоммерческого товарищества, предлагается решить следующим образом:

1. Необходимо учесть возможность проезда пожарной техники. Для определения нормативной ширины улиц и проездов в границах красных линий использовать нормативные документы, действовавшие на момент образования СНТ так как, СП 53.13330.2016 не учитывает исторически сложившиеся границы земельных участков и стесненные условия, в которых расположено СНТ «Мемориал4»[12]. Таким образом, предельные минимальные размеры земельных участков не будут нарушены. Так как ширина колеи транспортных средств для технического обслуживания составляет от 3,1 до 3,6 метров, то в соответствии с СП 99.13330.2016 «Внутрихозяйственные автомобильные дороги в колхозах, совхозах и других сельскохозяйственных предприятиях, и организациях» Актуализированная редакция СНиП 2.05.11-83*[3] ширину полосы движения необходимо увеличить до 4,5 метров. Увеличение ширины проездов в границах красных линий возможно за счет земельных участков сведения, о местоположении которых еще не внесены в ЕГРН [13]. В отношении земельных участков сведения, о местоположении которых внесены в ЕГРН с ошибкой необходимо выполнить уточнение местоположения границ земельных участков [14];

2. Тупиковые проезды, длина которых 150 метров, необходимо обеспечить разворотными площадками. В случае если длина тупиковых проездов превышает нормативные требования необходимо организовать дополнительные проезды между тупиковыми проездами за счет территорий свободных от застройки [15]; 
3. Контейнерную площадку необходимо разместить на свободной от застройки территории на расстоянии не менее 20 метров от границ существующих земельных участков [3].

\section{БИБЛИОГРАФИЧЕСКИЙ СПИСОК}

1. Земельный кодекс Российской Федерации от 25.10.2001 года N 136-Ф3// Собрание законодательства Томской области. - 2015. - № 7/2 (127).

2. СП 53.13330.2019 «Планировка и застройка территории ведения гражданами садоводства. Здания и сооружения (СНиП 30-02-97* Планировка и застройка территорий садоводческих (дачных) объединений граждан, здания и сооружения) // Российская газета. - № 151. 12.07.2019.

3. Мотошкина М.А., Норбоева Б.С., Аюшеева Д.М Современные проблемы дачных садоводческих некоммерческих объединений города Улан-Удэ и его пригорода // EARTH SCIENCES - 2019. - Вып. 1 (8) - C. 104-110.

4. СП 99.13330.2016 «Внутрихозяйственные автомобильные дороги в колхозах, совхозах и других сельскохозяйственных предприятиях, и организациях» Актуализированная редакция СНиП 2.05.11-83*. Российская газета. - № 151. - 12.07.2019.

5. Шаповалов Д.А., Хабаров Д.А. Проблемы и пути решения рационального использования земель сельскохозяйственного назначения // Землеустройство кадастр и мониторинг 2020 - Вып. 7 (7) - С. 31-35.

6. Willem Jan Wakker, Paul van der Molen and Christian Lemmen Land registration and cadastre in the Netherlands, and the role of cadastral boundaries// The application of GPS technology in the survey of cadastral boundaries. - 2018. - Vol. 46 (12). - C.1-10.

7. John D. Bossler, John C. Antenucci Toward a coordinated spatial data infrastructure for the nation. - 2nd ed. - New York : MAPPING SCIENCE COMMITTEE 2017 - 104 c.

8. Norton R.K. Using content analysis to evaluate local master plans and zoning codes // Land Use Policy. - 2008. - Vol. 25. - C. 432-454.

9. А.В. Гомозов, Л.В. Боева Анализ нормативных требований к проездам для пожарной техники // Earth Sciences - 2018. - Вып. 4 (5) - С. 98-102.

10. A.Z. Keller, L.Leckie Reliability Assessment of Fire-fighting Vehicles and Equipment// Ecosystem Services- 1992. - V. 27. - C. 432-454.

11. Clifton K., Currans K. Trip Generation Handbook. - 2nd ed. - Washington: The journal of transport and lend, $2004-164 \mathrm{c}$.

12. А.В. Зедгенизов , Д.В. Корчева Оценка транспорного спроса к садоводческим товариществам на основе количественных характеристик // Вестник ИРГТУ - 2015. - Вып. 6 (101) c. $119-123$.

13. S.B. Costelloa, D.N. Chapmanb, C.D.F. Rogersb, N. Metjeb Underground asset location and condition assessment technologi es // Tunnelling and Underground Space Technology. - 2007. Vol. 22. - P. 524-542.

14. Winnie Cheng, Esmond Mok Discourse processes and products: Land surveyors in Hong Kong // English for Specific Purposes. - 2008 Vol.27 (1). - C.5-7.

15. СП 42.13330.2011. «Градостроительство. Планировка и застройка городских и сельских поселений». Актуализированная редакция СНиП 2.07.01. 